\title{
BMJ Global Health Adverse effects of exposure to armed conflict on pregnancy: a systematic review
}

\author{
James Keasley, ${ }^{1}$ Jessica Blickwedel, ${ }^{1}$ Siobhan Quenby ${ }^{2}$
}

To cite: Keasley J, Blickwedel J, Quenby S. Adverse effects of exposure to armed conflict on pregnancy: a systematic review. BMJ Glob Health 2017;2:e000377. doi:10.1136/ bmjgh-2017-000377

Handling editor Seye Abimbola

- Additional material is published online only. To view please visit the journal online (http://dx.doi.org/10.1136/ bmjgh-2017-000377).

Received 20 April 2017 Revised 28 September 2017 Accepted 29 September 2017

CrossMark

${ }^{1}$ Warwick Medical School,

University of Warwick, Coventry, UK

${ }^{2}$ Division of Biomedical Sciences, Warwick Medical School, University of Warwick, Coventry, UK

Correspondence to James Keasley;

j.keasley@warwick.ac.uk

\section{ABSTRACT}

Introduction Exposure to armed conflict has manifold implications for both military and civilian populations. Prenatal stress has detrimental effects on both obstetric outcomes, fetal development and the development of an individual later in life. As well as causing stress to the mother, armed conflicts can decimate local infrastructures making it increasingly difficult to access antenatal and general healthcare. The present review is particularly salient in light of the many ongoing current conflicts. It examines the impacts of exposure to armed conflicts on the pregnancy outcomes.

Methods A thorough literature search was carried out on three databases using MeSH and truncation terms. 13 studies were included in the final analysis relating to mothers exposed to armed conflicts since 1990.

Results The studies include data from 1172151 patients: mothers from Libya, Bosnia, Herzegovina, Israel, Palestine, Kosovo, Yugoslavia, Nepal, Somalia, Iraq, Kuwait and Afghanistan. There is evidence of an increased risk of mothers giving birth to babies of low birth weight as reported in nine included studies. All have a degree of bias, with four at lower and five at higher risk of bias, either not adjusting for confounders or not employing robust measures of exposure to conflict. Further evidence suggested an increase in the incidence of miscarriage, stillbirth, prematurity, congenital abnormalities, miscarriage and premature rupture of membranes among mothers exposed to armed conflict.

Conclusion Despite the varying degrees of bias which must be considered for the available evidence, the data with the lowest risk of bias suggest a relationship between exposure to armed conflict and low birth weight. In light of the current level of displacement experienced by such populations, the identification of pregnancies at risk could improve the efficacy of antenatal care. Clinicians should consider additional ultrasound scanning where appropriate to monitor for restricted growth in such pregnancies.

\section{INTRODUCTION}

As of June 2017, 16 peacekeeping operations are being led by the United Nations (UN) across the world, working with countries torn by war and conflict. ${ }^{1}$ For those exposed to armed conflict, the implications are serious and wide reaching. ${ }^{2}$ Increasingly over recent decades, civilians have been caught in the

\section{Key questions}

What is already known about this topic?

- Civilians exposed to armed conflict are subject to persistent threats of bombing, and both biological and chemical weapons. Increasingly over recent years, it is these civilians who have been most adversely effected by wars, impacting both physical and mental health.

- Armed conflicts reduce healthcare provision through the destruction of infrastructure, food and water supplies and sanitation systems. This decreases the availability of antenatal and perinatal care for expectant mothers.

- Adverse outcomes in pregnancy are manifold. While pregnancy outcomes such as premature birth, stillbirths and low birth weight have been documented in individual studies, no systematic reviews have been conducted on this subject.

\section{What are the new findings?}

- This review included 13 studies. While the studies present evidence with varying degrees of bias, all studies measuring birth weight found a significant relationship between maternal exposure to armed conflict and increased rates of low birth weight.

- There was limited evidence suggesting significant positive relationships between armed conflict and miscarriage, stillbirth and prematurity.

- There was less evidence across the other studies investigating relationships between exposure to armed conflict and other adverse pregnancy outcomes such as rates of congenital abnormalities.

Recommendations for policy

- Given that mothers exposed to armed conflict are at a higher risk of giving birth to babies of low birth weight, clinicians must adjust care accordingly,that is, increase the frequency of ultrasound scans to track the growth of the baby and be prepared to intervene if required.

crossfire and have had to endure persistent threats of bombing, gunfire and attack by chemical and biological weapons. ${ }^{3}$ These pressures force many people to leave their homes and seek refuge in other countries. ${ }^{4}$ 


\section{War}

War, armed conflict, military conflict, fighting, military, genocide, warfare, military occupation, military attacks, war exposure

\section{Adverse outcome}

Adverse outcome, adverse event, stillbirth, miscarriage, spontaneous abortion, maternal morbidity, maternal mortality, mortality, premature, fetal mortality, perinatal mortality, prenatal mortality, embryo mortality, pregnancy complication, intrauterine growth restriction, low birth weight, premature fetus membrane rupture, pre-eclampsia, pregnancy outcome, premature labo\$r, premature labor obstetric labour, premature, intrauterine growth retardation, fetal growth retardation, growth restriction, growth retardation

Pregnancy

Pregnancy, pregnan*, gravid, gestation, mother, childbirth, birth, parturition

Underlined terms=MEsH terms

Figure 1 Search terms.

The changing landscape of war has also meant that now $>90 \%$ of war casualties are civilians compared with only $5 \%$ in World War I. ${ }^{5}$ In addition, women and children are particularly vulnerable to the adverse effects of conflict. ${ }^{6}$

Long-term health effects of exposure to armed conflict have been documented extensively, both in military and civilian populations; in particular, mental health conditions such as post-traumatic stress disorder ${ }^{7}$ are highly prevalent. The short-term and medium-term health consequences of exposure to armed conflict are also manifold. Hospitals are often targets of attacks, resulting in significantly reduced healthcare provisions for civilians. ${ }^{8}$ Armed conflict also causes disruptions in food supplies, water supplies and sanitation systems, the results of which all increase the risk of communicable diseases. ${ }^{9}$ Furthermore, the indirect impacts of war can have longlasting detrimental effects on countries. Health services, for instance, are often severely interrupted by the destruction of infrastructure and management systems. ${ }^{10}$ The many challenges for rebuilding these services mean that health provision can be disrupted for years after the cease of conflict. ${ }^{112}$

This systematic review focuses on the effects of exposure to armed conflict on pregnant women, for whom conflict can mean a disruption to antenatal care, a decreased number of trained birthing attendants available at delivery and increased maternal stress (shown to raise levels of maternal cortisol and associated with long-term adverse consequences for the child).${ }^{13}$ Armed conflict can also result in violence against women ${ }^{14-16}$ and reduced provision of emergency care ${ }^{17}$ This review examines both armed conflicts in which women were subjected to acute stressful events (such as explosions and other severe life-threatening events) as well as chronic stressful events of war (such as fleeing conflict and disruptions to food and medical supplies). It investigates the extent to which stresses associated with exposure to armed conflicts affect the incidence of adverse outcomes in pregnancy, including premature birth, stillbirths and low birth weight. Finally, the review considers both immediate consequences, affecting pregnancies at the time of exposure, as well as longer-term consequences, affecting women years after exposure.

The present review is particularly salient in light of the many ongoing current conflicts. Syria, in particular, which has featured heavily in global news, has seen large numbers of people forced to flee their homes, resulting in 1177914 new asylum applications to European countries between April 2011 and September 2016. ${ }^{4}$ It is thus crucial to fully understand the implications of exposure to armed conflicts on pregnancy to provide the most appropriate level of care to these women.

\section{METHODS}

Three databases were searched: MEDLINE, Web of Science and Embase. The search terms are outlined in figure 1 .

Studies were assessed for the following criteria: inclusion criteria: English language, human studies, studies after 1990 (and related to armed conflicts starting after 1990), include more than five patients, quantitative data and peer-reviewed studies with statistical analysis. Exclusion criteria: military personnel, editorials and letters. The search terms were refined following consultations with a clinical evidence specialist.

The final search was conducted on 13 October 2016. In addition, the ancestry method was employed to ensure completeness, that is, bibliographies of relevant studies were screened to identify any further studies. No additional articles were identified. A preliminary grey literature search was conducted but no relevant studies were identified. Following this search, the authors agreed only to include peer-reviewed, published papers.

The studies were independently screened by two authors, rejecting studies for which the titles and abstracts did not meet the inclusion criteria or met the exclusion criteria. The remaining 54 studies were also independently assessed for eligibility; if they did not meet the criteria for inclusion, they were documented in a table, accompanied by the reasoning (see online supplementary appendix x). In total, there were disagreements about the inclusion of six studies $(11.1 \%)$. These discrepancies were discussed until agreement was reached for all. The screening process is detailed in the Preferred Reporting Items for Systematic Reviews and Meta-Analyses (PRISMA) flow diagram (figure 2).

Following this, the quality of the studies was assessed using checklists from the Scottish Intercollegiate Guidelines Network (SIGN) 50. SIGN was formed in 1993, with the aim of 'reducing variation in practice and outcome, through the development and dissemination of clinical guidelines'. ${ }^{18}$ SIGN was chosen over other checklists such as PRISMA and Strengthening the Reporting of Observational Studies in Epidemiology because after discussion it was deemed the most appropriate for the review 


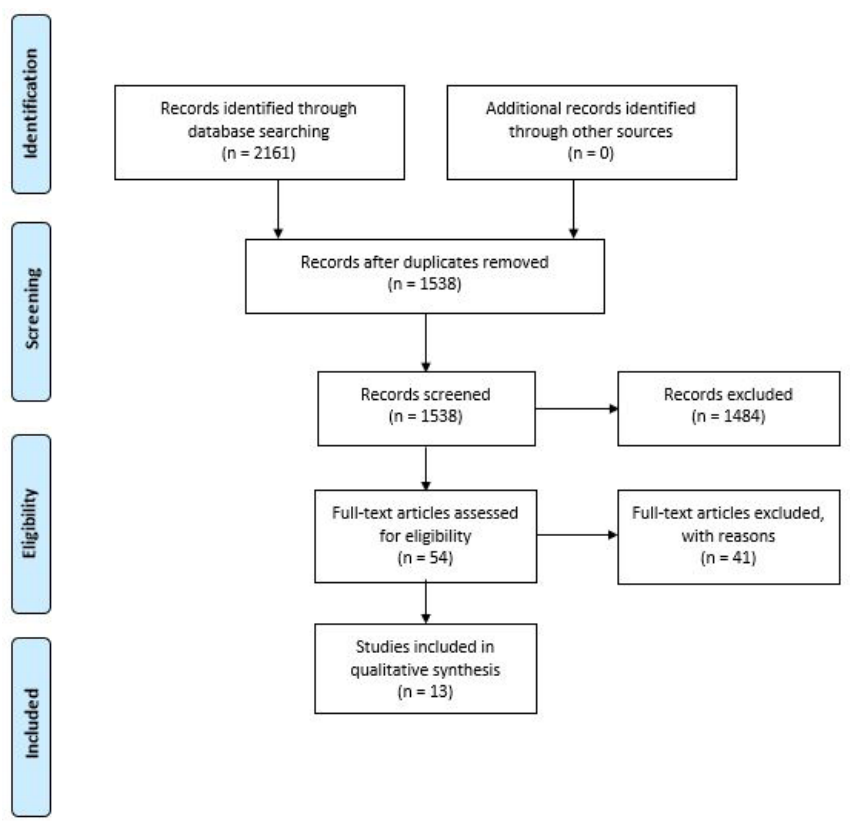

Figure 2 Preferred Reporting Items for Systematic Reviews and Meta-Analyses flow diagram.

question. ${ }^{19}$ No other system was regarded more appropriate for assessing the quality of studies such as interrupted time series. The studies were given two scores: a level of evidence score and a methodology checklist score. SIGN 50 develops 'evidence-based clinical practice guidelines' for Scotland. ${ }^{20}$ The checklists provide researchers with the tools to grade the quality of evidence in studies across the spectrum of study designs. The basis of the checklists is to detect the risk of bias in studies and to rate the evidence on a scale. The level of evidence score ranges from $1++$ (high-quality meta-analyses, systematic reviews of randomised controlled trials (RCTs) or RCTs with a very low risk of bias) to 4 (expert opinion). All of the studies included were either rated as 2+ (well-conducted case-control or cohort studies with a low risk of confounding or bias as moderate probability that the relationship was casual) or 2- (case-control or cohort studies with a high risk of confounding or bias and a significant risk that the relationship is not causal). The methodology checklist score is more rudimentary. The checklists differ for each study design, but the scoring system is consistent among checklists. The studies are deemed to be high quality $(2+)$, acceptable $(1+)$ or unacceptable $(0)$. While the aim of the checklists is to provide a systematic method for appraising evidence, the checklists are not objective and ultimately reflect researchers' opinions about the quality of evidence. SIGN 50 does not provide appraisal tools for cross-sectional studies or interrupted time series. As such, the decision was made to use the cohort study checklists to screen for bias, in line with previous systematic reviews. $^{21}$

Data were extracted from 18 studies. Of these, five were rejected from the qualitative synthesis on grounds of their insufficient quality being graded with both a
2- on the level of evidence scale and a 0 (unacceptable) on the methodology checklist scale. The data extracted from the studies were recorded in a comprehensive data extraction table and later condensed into the final results tables (see online supplementary appendix tables 1, 2, 3).

\section{Definitions}

This study defined armed conflicts in broad terms, in line with the International Committee of the Red Cross and international humanitarian law to include both international armed conflicts (involving two or more opposing states) and non-international armed conflicts (between governmental forces and non-governmental armed groups). ${ }^{22}$ This study considered armed conflict to involve exposures to physical, biological and chemical warfare. The study did not include one-off acute life-threatening events such as the attack on the World Trade Center.

Adverse pregnancy outcomes were also defined in broad terms, with individual study outcomes detailed in the results tables. The outcomes measured in the review included preterm labour, post-term labour, low birth weight, stillbirth, spontaneous abortion (miscarriage), small for gestational age, premature rupture of membranes, early neonatal mortality and perinatal mortality and maternal mortality.

Due to the heterogeneity of study designs, it was deemed inappropriate to perform a meta-analysis on the included studies; therefore, the results are synthesised in a narrative analysis.

\section{RESULTS}

Thirteen studies are included in the analysis. Five further studies were rejected on grounds of a high risk of bias as a result of methodological design. ${ }^{523-26}$ The studies relate to mothers from 12 countries affected by armed conflict; 2 studies relating to participants from either Iraq or Kuwait during the 1990-1991 Gulf war, ${ }^{27} 1$ study relating to Libya, $^{29} 4$ relating to Bosnia and Herzegovina, ${ }^{30-33} 3$ relating to Israel and Palestine since 2000, ${ }^{34-36} 1$ relating to Kosovo and Yugoslavia ${ }^{37}$ and 1 relating to Nepal. ${ }^{38}$ There was also one study relating to refugees settling in Norway; these women were from Somalia, Kosovo, Iraq and Afghanistan. ${ }^{39}$ There were four different study designs: two retrospective cross-sectional studies, ${ }^{27} 29$ one prospective cohort study, ${ }^{39}$ three retrospective cohort studies $^{34-36}$ and seven interrupted time series. ${ }^{28-33} 38$ In total, the studies include data from 1172151 participants. However, the three studies with the most participants, ${ }^{30-32}$ accounting for 1127614 participants, are also those with some of the weakest 'level of evidence' scores (with SIGN 50 scores of 2- and 1+ on the methodology checklist). The studies with the strongest level of evidence scores and a SIGN 50 grade of 2+ analyse data from 29148 participants.

The tables present information on both the significant and non-significant data from the studies. If $p$ values or OR 
values relating to the outcomes were given in the studies, they have been included in the tables. The 'measure of exposure/length of exposure' column relates to how long the population was exposed to specific aspects of armed conflict and outlines the specific exposures that the authors cite as constituting war stressors. This information was not available for every study.

\section{Low birth weight}

Four studies focus primarily on low birth weight ${ }^{3032} 3235$ and a further five studies measure it as an outcome. ${ }^{27-2931} 39$ All studies indicate a significant relationship between exposure to armed conflict and a detrimental effect on birth weight, four of which have a low risk of bias as indicated by their SIGN score; Arnetz et $a t^{27}(\mathrm{p}=0.017$, OR 3.00), Mansour et $a l^{35}(\mathrm{p}<0.05)$, Maric et $a l^{37}(\mathrm{p}<0.001)$ and Bakken et $a e^{39}$ (OR 3.97). Studies evaluated this relationship in three ways. (1) The OR of a woman giving birth to a low birthweight child if exposed to specific chemicals was calculated compared with a control group. (2) The rate of low birthweight babies during a war period compared with the prewar/postwar rates. (3) The percentage increase risk of having a low birth weight baby is calculated by examining the intensity of conflict in a mother's place of residence. Interestingly, the only study to examine the trimester of exposure noted no significant relationship between the trimester of stress exposure and birth weight in infants born during the period. ${ }^{37}$ In comparison to the other studies, this study had a low risk of bias (see online supplementary appendix table 1).

\section{Stillbirth}

Stillbirth was measured in five studies. ${ }^{2728313338}$ Of these, only one demonstrated a significant increase in the rate of stillbirth $(p<0.01)$; this was shown in relation to contact with specific chemical exposures in the 1990-1991 Gulf War such as smoke from oil well fires, exhaust fumes from kerosene heaters and generators, diesel fumes, mustard gas and food contaminated with smoke, oil or other chemicals. ${ }^{27}$ This study was among those with the lowest risk of bias. Three studies, two with higher risks of bias and another with a low risk of bias, showed no significant difference in the rates of stillbirth when considering exposure to armed conflict. ${ }^{28} 3138$ The Pavlinac et al study even showed significant decreases in the overall rates of stillbirth among all singleton births. ${ }^{33}$ This study also demonstrates that there was a significant increase in stillbirths among mothers who had preterm births $(\mathrm{p}<0.001)$ (see online supplementary appendix table 2 ).

\section{Prematurity}

Prematurity was measured in eight studies. Four studies demonstrated a statistically significant increase in premature births. ${ }^{27293134}$ Of these, the Arnetz et $a l^{27}$ and Keren et $a l^{34}$ studies have lower risks of bias than the Skokic et $a l^{31}$ and Bodalal $e t a l^{29}$ studies. Arnetz et al measure exposures to specific chemicals and report increases in the rates of prematurity. In contrast, one study with a low risk of bias compared with the other included studies found an increase in post-term births in Somalian women ${ }^{39}$ exposed to armed conflict and another study showed a significant decrease in the number of premature deliveries during the war. ${ }^{33}$ However, Pavlinac et $a \hat{l}^{33}$ found that within the population of premature babies both stillbirth and early neonatal mortality rates increased during the period of armed conflict. The other studies found no such significant relationship between armed conflict and prematurity $^{2837}$ (see online supplementary appendix table 2).

\section{Other}

Other adverse pregnancy outcomes were addressed to a lesser extent. Three studies discuss congenital abnormalities: two studies, only one of which had a relatively low risk of bias, ${ }^{27}$ found significant increases (either in specific types of congenital abnormalities or rates in mothers exposed to diesel fumes) ${ }^{2728}$ while a third study found no significant difference. ${ }^{37}$ Two other high-quality articles by Valente and Wainstock et al considered rates of miscarriage. ${ }^{36}$ Wainstock et al found a significant increase, and while the Valente study found a positive correlation between exposure to armed conflict and miscarriage, this finding was not significant. These results did not show a simple dose relationship. ${ }^{36}$ Wainstock et al, for instance, found that mothers with both the highest and lowest exposure rates during pregnancy in the sample were at the highest risk of miscarriage. In the same study, mothers with the highest rates of exposure preconception were at greatest risk of miscarriage in relation to those mothers with lower grades of preconception exposure. In addition, premature rupture of amniotic membranes was mentioned in two studies, both with lower risks of bias; one found a significant increase during the war years and another found no significant differences in the prewar /war period rates. ${ }^{3437}$ Two studies with higher risks of bias also examined early and perinatal mortality. ${ }^{32} 33$ These both relate to the armed conflict in Bosnia. The studies found different results. Pavlinac ${ }^{33}$ found that, overall, early neonatal deaths decrease significantly both during and after the war. However, in contrast, when limiting the analysis to early neonatal deaths of only premature births during the armed conflict, there was a significant increase in the early neonatal mortality rate. Skokic ${ }^{32}$ found a significant increase in both neonatal and perinatal mortality during the period of armed conflict $(\mathrm{p}<0.001$, $<0.05)$. Three additional studies examine other complications including meconium-stained liquor, pre-eclampsia, maternal mortality, placental abruption, placenta previa, perineal rupture, postpartum bleeding $>500 \mathrm{~mL}$, umbilical cord complications, neonatal jaundice, rhesus incompatibility, breech birth, shoulder dystocia, fetal asphyxia and hydropic newborns. ${ }^{3133} 3739$ Of these, only meconium-stained liquor was found to be significantly increased-this was within the population of Somalian mothers who sought asylum in Norway and gave birth outside Somalia. ${ }^{39}$ Such a significance was not found in 
the other refugee populations. Skokic et al observed that maternal mortality rates were increased during periods of armed conflict $(\mathrm{p}<0.001) .{ }^{31}$ There was a higher risk of bias in this study. Maric et al, in contrast, reported a significant decrease in the rates of pre-eclampsia during the armed conflict (OR $0.592,95 \%$ CI 0.407 to 0.863$){ }^{37}$ This study had a lower risk of bias (see supplementary appendix table 3 ).

\section{Confounders}

Many different confounders were measured in the studies including smoking status, newborn sex, income, health insurance coverage, education, employment, ethnicity, maternal age, parity, gravidity, mode of conception, previous stillbirths/caesarean sections, pre-gravid health conditions, time spent in country of refuge, marital status and district of residence, anaemia and obstetric history. Taking Wainstock et al as an example, many studies show that confounders are significantly related to pregnancy outcomes. For instance, there are many indicators significantly related to miscarriage rates in the sample population. $^{36}$ These include maternal age $>35(\mathrm{p}=0.001)$, unmarried women $(p=0.004)$ and having had four or more pregnancies $(\mathrm{p} \leq 0.001)$. Women with a history of two or more abortions were also at a greater risk, though this only reached borderline significance $(\mathrm{p}=0.061)$. Three studies did not measure confounders; however, all of these studies had very large sample sizes. ${ }^{28-30}$ Skokic et al also found statistical significance between low birth weight and number of antenatal visits. ${ }^{32}$

Only one study examined the trimester of pregnancy and exposure to armed conflict in the data analysis. ${ }^{37}$ No statistically significant difference was found in birth weights between groups exposed at different periods throughout pregnancy.

\section{DISCUSSION}

The results suggest that exposure to armed conflict increases the incidence of adverse outcomes in pregnancy. The extent to which this is the case cannot be easily quantified. The most convincing evidence suggests that the incidence of low birthweight infants increases with maternal exposure to armed conflict. Four of the nine studies reporting this significant relationship between exposure to armed conflict and low birth weight have been assessed to have a relatively low risk of bias. The effect sizes from the other five studies, however, may have a higher risk of bias due to the lack of adjustment for confounders and limited data on measures of exposure to conflict. In addition, there is some more limited evidence supporting increased rates of miscarriage, prematurity, stillbirth, premature rupture of membranes and congenital abnormalities.

However, the heterogeneity of the available research does cause some difficulty in assessing the overall available evidence. The included studies considered a wide range of different sample populations. For instance,
Pavlinac et al provide data on a specialist tertiary centre (dealing with a higher proportion of high-risk pregnancies), whereas Skokic et al focus on a regular obstetric clinic. As the specialist centre will be providing care for more complex cases, we may expect to have higher rates of adverse outcomes. In addition, the measures of exposure used varied across studies; while some used more general indicators such as country of birth to measure exposure ${ }^{39}$ others considered much more specific indicators through the use of exposure questionnaires ${ }^{27}$ or through consideration of exact dates of birth in relation to the most intense periods of armed conflict. ${ }^{37}$ Finally, it is challenging to compare studies directly due to heterogeneity in reporting of statistics with some authors providing solely $\mathrm{p}$ values or OR values within the original research paper.

There are several limitations to this review. Many of the studies did not fit neatly into the SIGN 50 study design classification algorithm or, because they were cross-sectional or interrupted time series, were deemed to be low-quality evidence. In addition, as with all systematic reviews, there is the potential for publication bias, namely that the evidence published is skewed in favour of significant positive findings. The review does not consider grey literature. While organisations such as the UN, Médécins sans Frontières and the Red Cross do collect wartime data, after a preliminary grey literature search the authors agreed only to include peer-reviewed studies. Finally, this review only considers studies written in English-widening the scope may have yielded some further evidence on this global topic.

There were also several common themes in the limitations described by the studies, many of which are related to the constraints of conducting a study in this field. Armed conflict limits the opportunities to collect complete sets of data and the fact that researchers are not always anticipating armed conflict means that they are often restricted with the types of studies that they can perform. Indeed, many studies were rejected from inclusion in this review because they were solely descriptive, identifying broad trends but not including enough data to perform statistical analysis. In addition, the limited data on confounding factors are expected to have influenced the results of the studies. This is likely due to the lack of available data rather than weak methodologies. Furthermore, the totality of armed conflict means that many different factors play roles in influencing the rate of adverse outcomes in pregnancy. As Valente comments, 'it is difficult to pinpoint the relative importance of each of these sources of maternal stress' when contextualising the findings of these studies. ${ }^{38}$ As a result, even some of the studies that were included in the final synthesis had a relatively strong risk of bias. Three of the studies relating to low birth weight, for example, have a weak level of evidence despite having the largest numbers of participants. ${ }^{30-32}$ Indeed seven of the studies included in the synthesis are interrupted time series. While these concerns do not suggest that the evidence should be 
disregarded, it should be considered in the context of the practicalities of data collection during or after a war. In particular, the effect sizes of the three studies mentioned with large numbers of participants may have a higher risk of bias. In addition, there is limited adjustment for confounders in some of the studies. ${ }^{28-30}$ However, the authors suggest that conclusions may still be drawn from the four other studies considering low birth weight that have a relatively low risk of bias. ${ }^{27} 353739$

In addition, several of the studies relate to countries which have a long history of short armed conflicts or short periods of peace between longer armed conflicts; this means that many of the control populations could well have been exposed to similar conflicts in the past. This is particularly pertinent for the armed conflicts in Israel, Palestine, Iraq and Somalia. It also suggests that any distinctions made between the effects of acute rather than chronic armed conflict may be more challenging to make. Furthermore, none of the studies define war or armed conflict in general terms, again making it difficult to distinguish between the effects of various aspects of armed conflict (eg, acute stressful events compared with long-term disruption of medical facilities). Ultimately this makes it challenging to fully comprehend the short-term or long-term effects of armed conflicts on pregnancy.

\section{CONCLUSION}

In conclusion, the evidence reviewed in this study suggests that exposure to armed conflict has a multitude of effects on outcomes in pregnancy. In particular, exposure to armed conflict increases the risk of having low birthweight infants. The long-term health implications of low birth weight are significant because individuals are at increased risk of morbidity and mortality and will require increased medical care throughout their lives. ${ }^{40}$ While the evidence for other outcomes is less strong, the review also identifies increased incidence of adverse outcomes in mothers exposed to armed conflict. Further well-conducted studies are needed to add weight to conclusions drawn so far. Nonetheless, the findings of this review should be borne in mind when treating patients exposed to armed conflict and systems should be implemented to support these individuals. Clinicians should consider using ultrasound scans more frequently in the cases of such mothers in order to effectively care for patients who are at a higher risk of giving birth to an infant of low birth weight. This will only be possible if warring parties are committed to following the Geneva Convention, refrain from attacking healthcare facilities and workers, and are adequately resourced. ${ }^{41}$ Until this happens, women and their infants will be at continued risk of adverse outcomes in pregnancy. Recommendations about pregnancy monitoring are also particularly important to consider for clinicians in other countries, who may be treating women displaced due to armed conflict.

Contributors All authors had full access to all of the data (including statistical reports and tables) in the study and can take responsibility for the integrity of the data and the accuracy of the data analysis. All authors read final manuscript and approved it.

Competing interests None declared.

Provenance and peer review Not commissioned; externally peer reviewed.

Open Access This is an Open Access article distributed in accordance with the Creative Commons Attribution Non Commercial (CC BY-NC 4.0) license, which permits others to distribute, remix, adapt, build upon this work non-commercially, and license their derivative works on different terms, provided the original work is properly cited and the use is non-commercial. See: http://creativecommons.org/ licenses/by-nc/4.0/

(c) Article author(s) (or their employer(s) unless otherwise stated in the text of the article) 2017. All rights reserved. No commercial use is permitted unless otherwise expressly granted.

\section{REFERENCES}

1. United Nation Po. Current peacekeeping operations. $2016 \mathrm{http}: / /$ www.un.org/en/peacekeeping/operations/current.shtml (accessed 29 Nov 2016).

2. United Nation Peacekeeping. United Nations Peacekeeping helps countries torn by conflict create the conditions for lasting peace. We are comprised of civilian, police and military personnel. http://www. un.org/en/peacekeeping/about/ (accessed 30 Jun 2016).

3. Aljazeera report on 2016 UN data. http://www.aljazeera.com/news/ 2017/02/afghan-civilian-casualties-2016-170206062807210.html (accessed 30 Jun 2016).

4. UNHCR TURA. Syria regional refugee response. $2016 \mathrm{http} / / /$ data. unhcr.org/syrianrefugees/asylum.php (accessed 29 Nov 2016).

5. Fatusić Z, Kurjak A, Grgić G, et al. The influence of the war on perinatal and maternal mortality in Bosnia and Herzegovina. $J$ Matern Fetal Neonatal Med 2005;18:259-63.

6. Miller LC, Timouri M, Wijnker J, et al. Afghan refugee children and mothers. Arch Pediatr Adolesc Med 1994;148:704-8.

7. Xue $\mathrm{C}, \mathrm{Ge} \mathrm{Y}$, Tang B, et al. A meta-analysis of risk factors for combat-related PTSD among military personnel and veterans. PLoS One 2015;10:e0120270.

8. Amnesty International. Syrian and russian forces targeting hospitals as a strategy of war. https://www.amnesty.org/en/press-releass/ 2016/03/syrian-and-russian-forces-targeting-hospitals-as-astrategy-of-war (accessed 28 Jun 2016).

9. Gayer M, Legros D, Formenty P, et al. Conflict and emerging infectious diseases. Emerg Infect Dis 2007;13:1625-31.

10. Ahamadani FAB, Louis $\mathrm{H}$, Ugwi $\mathrm{P}$, et al. Perinatal health care in a conflict-affected setting: evaluation of health-care services and newborn outcomes at a regional medical centre in Iraq. East Mediterr Health J 2014;20:789-95.

11. Gure F, Yusuf M, Foster AM. Exploring Somali women's reproductive health knowledge and experiences: results from focus group discussions in Mogadishu. Reprod Health Matters 2015;23:136-44

12. Omeragic F. Bosnia-Herzegovina: a case study in service collapse. Safe motherhood. Entre Nous Cph Den 1998;38:12.

13. Davis EP, Sandman CA. The timing of prenatal exposure to maternal cortisol and psychosocial stress is associated with human infant cognitive development. Child Dev 2010;81:131-48.

14. Cottingham J, García-Moreno C, Reis C. Sexual and reproductive health in conflict areas: the imperative to address violence against women. BJOG 2008;115:301-3.

15. Stark L, Roberts L, Wheaton W, et al. Measuring violence against women amidst war and displacement in northern Uganda using the "neighbourhood method". J Epidemiol Community Health 2010;64:1056-61.

16. Dossa NI, Zunzunegui MV, Hatem M, et al. Fistula and other adverse reproductive health outcomes among women victims of conflictrelated sexual violence: a population-based cross-sectional study. Birth 2014;41:5-13.

17. Ameh CA, Bishop S, Kongnyuy E, et al. Challenges to the provision of emergency obstetric care in Iraq. Matern Child Health $J$ 2011;15:4-11.

18. SIGN. 'Who we are'. http://www.sign.ac.uk/who-we-are.htm (accessed 28 Jun 2016).

19. Katrak P, Bialocerkowski AE, Massy-Westropp N, et al. A systematic review of the content of critical appraisal tools. BMC Med Res Methodol 2004;4:22.

20. Guidelines Network SI. What is SIGN? 2015 http://www.sign.ac.uk/ about/introduction.html (accessed 29 Nov 2016). 
21. van Ool JS, Snoeijen-Schouwenaars FM, Schelhaas HJ, et al. A systematic review of neuropsychiatric comorbidities in patients with both epilepsy and intellectual disability. Epilepsy Behav 2016;60:130-7.

22. Red Cross ICot. How is the Term "Armed Conflict" Defined in International Humanitarian Law? 2008 https://www.icrc.org/eng/ assets/files/other/opinion-paper-armed-conflict.pdf (accessed 29 Nov 2016)

23. Naim A, Al Dalies H, El Balawi M, et al. Birth defects in Gaza: prevalence, types, familiarity and correlation with environmental factors. Int J Environ Res Public Health 2012;9:1732-47.

24. Radoncić F, Hudić I, Balić A, et al. Perinatal outcomes during 19862005 in Tuzla Canton, Bosnia and Herzegovina. J Matern Fetal Neonatal Med 2008;21:567-72.

25. Schenker E, Mor-Yosef S. Did anxiety during the Gulf War cause premature delivery? Mil Med 1993;158:789-91.

26. Simic S, Idrizbegovic S, Jaganjac N, et al. Nutritional effects of the siege on new-born babies in Sarajevo. Eur J Clin Nutr 1995;49(Suppl 2):S33-S36.

27. Arnetz B, Drutchas A, Sokol R, et al. 1991 Gulf War exposures and adverse birth outcomes. US Army Med Dep J 2013:58-65.

28. Makhseed M, el-Tomi N, Moussa MA, et al. Post-war changes in the outcome of pregnancy in Maternity Hospital, Kuwait. Med Confl Surviv 1996;12:154-67.

29. Bodalal Z, Agnaeber K, Nagelkerke N, et al. Pregnancy outcomes in Benghazi, Libya, before and during the armed conflict in 2011. East Mediterr Health J 2014;20:175-80.

30. Brialić I, Rodin U, Vrdoljak J, et al. Secular birth weight changes in liveborn infants before, during, and after 1991-1995 homeland war in Croatia. Croat Med J 2006;47:452-8

31. Skokić F, Muratović S, Radoja G. Perinatal and maternal outcomes in Tuzla Canton during 1992-1995 war in Bosnia and Herzegovina. Croat Med J 2006;47:714-21.
32. Skokić F, Bačaj D, Selimović A, et al. Association of Low Birth Weight Infants and Maternal Sociodemographic Status in Tuzla Canton during 1992-1995 War Period in Bosnia and Herzegovina. Int J Pediatr 2010;2010:1-7.

33. Pavlinac I, Marin A, Valić M, et al. Influence of the wars in Croatia and Bosnia and Herzegovina on the incidence and outcome of singleton premature births in the split university hospital. Open Med 2008;3:187-93.

34. Keren M, Keren N, Eden A, et al. The complex impact of five years of stress related to life-threatening events on pregnancy outcomes: a preliminary retrospective study. Eur Psychiatry 2015;30:317-21.

35. Mansour H, Rees DI. Armed conflict and birth weight: Evidence from the al-Aqsa Intifada. J Dev Econ 2012;99:190-9.

36. Wainstock T, Lerner-Geva L, Glasser S, et al. Prenatal stress and risk of spontaneous abortion. Psychosom Med 2013;75:228-35.

37. Maric NP, Dunjic B, Stojiljkovic DJ, et al. Prenatal stress during the 1999 bombing associated with lower birth weight-a study of 3,815 births from Belgrade. Arch Womens Ment Health 2010;13:83-9.

38. Valente C. Civil conflict, gender-specific fetal loss, and selection: a new test of the Trivers-Willard hypothesis. J Health Econ 2015;39:31-50

39. Bakken KS, Skjeldal OH, Stray-Pedersen B. Immigrants from conflict-zone countries: an observational comparison study of obstetric outcomes in a low-risk maternity ward in Norway. BMC Pregnancy Childbirth 2015;15:163-75.

40. Risnes KR, Vatten LJ, Baker JL, et al. Birthweight and mortality in adulthood: a systematic review and meta-analysis. Int $J$ Epidemiol 2011;40:647-61.

41. International Committee of the Red Cross. Treaties state parties and commentaries. https://ihl-databases.icrc.org/applic/ihl/ihl.nsf/ INTRO/615?OpenDocument (accessed 30 Jun 2016). 